\title{
Critical success factors for human resource management of construction project
}

\author{
Sepideh Leilaee $^{\mathrm{a}^{*}}$ and Javad Rezaeian ${ }^{\mathrm{a}}$
}

${ }^{a}$ Mazandaran University of Science and Technology, College of Management and technology, Babol, Iran

\section{H R O N I C L E}

\section{Article history:}

Received: July 1, 2020

Received in revised format:

February 20, 2021

Accepted: April 4, 2021

Available online:

April 4, 2021

Keywords:

Critical Success Factors

Project Management

Human Resource Management

Multi-criteria decision making

\section{A B S T R A C T}

The characterization of project critical success factors is a multidimensional construction that relies upon numerous components. This investigation analyzes the various criteria and components that impact the accomplishment of the tasks in the human resource region of the development project. This examination utilizes a comparative method, the analytic network process method is used to recognize the significant weight of models lastly, the positioning is finished by the Technique for Order of Preference by Similarity to Ideal Solution technique, to analyze 27 critical success factors in the human resource management in project, and thinks about a wide scope of progress rules and basic achievement factors. The outcomes and assessment of specialists illustrate, select increasing trust and certainty among employees and project team managers, and it has the most effect on the accomplishment of Human Resource Management in projects. Contributing to these factors will improve the effectiveness of the activities.

\section{Introduction}

The common pattern towards economic growth in creating nations has brought about a high demand for construction project delivery (Zhang et al., 2014) which has eclipsed concerns (Chang et al., 2016). For example, numerous industry areas, information technology, executives counseling, and construction, are progressively project-based, among which development is presumably the biggest and most complex one (Sydow et al., 2004; Cheng et al., 2005; Whitley, 2006). The previous few decades have seen a fast extension in the range and effect of project management (PM) (Morris, 2013; Shenhar \& Dvir, 2007), eminently so outside its conventional heartlands in development and building. Because of the socio-cultural and financial peculiarities of creating nations (Elkhalifa, 2016), setting explicit critical success factors (CSFs) should be created to help venture administrators. (Gan et al., 2015; Othman \& Ahmed, 2013; Pade et al., 2008). Identifying success factors of construction projects is the most important issue in the field of project management. Identifying and prioritization of these Factors, it can provide a good framework for evaluation and check out the project outputs for managers, employers, and contractors. Furthermore, the recognition of the success factors of projects can help appropriate allocation management during the project (Amini et al., 2012). HRM is approach and vision about the development of manpower, to utilization from that, in the direction to improve group performance of projects and Creation Organizational Competitive Advantage (Hafezi et al., 2015), Considered for reaching the conquest on projects (Cooke-Davies, 2002; Chan et al., 2001). In the construction industry are working various workforce; therefore, Human resources management it's a challenging job in this industry. Specifically, an investigation of literature uncovers an obvious nonattendance of studies on recognizing CSFs of human resources in construction projects in developing countries. To close this gap in the structure of information, the goal of this investigation is to find the CSFs to indicate the significance of the management and association in HR of the project and recognize their effect on construction projects improve in developing countries. The research steps are described below. Firstly, the foundation to the study

* Corresponding author.

E-mail address: sepidehleilaee@gmail.com (S. Leilaee) 
problem, the process toward gathering CSFs from the literature and specialist's idea. A while later, the study methods and the structure of the examination are clarified. At the end, introducing the results of investigation followed by an argument on these conclusions.

In this study, by distinguishing the components and afterward organizing them, endeavors were made to investigate. Toward the end, it is a multi-dimensional complex decision-making (MCDM) issue that comprises a diversity of decision-makers. MCDM techniques are alluring methodologies for the prioritization of Critical Success Factors, and as of late their notoriety has developed among researchers attributable to their significant level of efficiency. Because of the significance of project success, the identify and prioritization of Critical Success Factors in Human Resource Management is a mind -boggling choice issue. With this examination, we propose an Analytic Network Process (ANP) weighted Technique for Order Performance by Similarity to Ideal Solution (TOPSIS) strategy to beat the complexities of this decision-making process. Despite the fact that the writing incorporates various examinations where ANP and TOPSIS strategies are utilized exclusively or in some mix, this investigation offers extra commitments to the surviving literature. However, there are many successful usages of TOPSIS and/or ANP to a large area of MCDM difficulties in different scopes, there is no application of a based ANP-weighted TOPSIS methodology for the prioritization of Critical Success Factors in Human Resource Management of the construction project.

\section{Literature review}

In late decades, the governments of developing countries have distributed generous measures of capital budget plans to the framework, transport, and private undertakings (Chang et al., 2016; Gan et al., 2015; Zhang et al., 2014). In developing countries, construction projects have high effects on networks, the environment, and social characteristics (Van Marrewijk et al., 2008) with a gigantic load inside the economy (Chang et al., 2016; Ghoddousi \& Hosseini, 2012). Due to the Othman and Ahmed (2013), the primary difficulties impacting the supportable delivery of projects go under five significant groups in developing countries. These are specialized, human development, administrative, political and triple bottom line (TBL), with TBL alluding to ecological, social, and financial difficulties. Of these, administrative difficulties were seen as the most effective (Othman \& Ahmed, 2013). Due to many studies accomplished on project managers, these researches fall project managers into five groups: (1) studies conducted on the qualification of project managers, such as Cheng et al. (2005)in construction and Crawford (2000)in common; (2) researches on the election of project managers, such as Mohammadi et al. (2014) in construction and Ahsan et al. (2013)in common; (3) researches on the guidance of project managers, such as Bossink (2004)in construction and Turner and Müller (2005)in common; (4) researches on the individuality and emotional intelligence (EI) of project managers, such as Zhang and Fan (2013) in construction and Dolfi and Andrews (2007); and (5) researches on the task of project managers, such as Sommerville et al. (2010) in construction and Ammeter and Dukerich (2002)in common . In the past years, skilled project managers have assumed an increasingly indispensable role in the project executives. Moreover, organizations put forth significant attempts to seek capable project managers, for example, compensation improvement (Acharya et al., 2016; Giannetti, 2011). Projects are executed to accomplish a specific objective and chosen targets. Notwithstanding the iron triangle destinations of scope, time, and cost, organizations are progressively worried about a project's more extensive advantages and worth (Silvius and Schipper, 2014). In 1960, several studies were done on the importance of effective factors, Belassi and Tukel (1996), in their review notation that the success and failure factors were first presented by Rubin and Seeling (1967) in the content of project management. Rockart was the first to use the terminology of critical success factors (CSFs) for project management (1982 cited in Savindo et al., 1992). The phrase "critical success factor" or CSF points certain origin which significantly contributes to, and is fundamental for, the success of a project (Ika \& Hodgson, 2014). Projects may succeed and reject regarding how they arrive at their purposes and how they are managed (Lehtonen $\&$ Martinsuo, 2006). The problem which is specialized in project management is that achievement is a vague, comprehensive, and multidimensional idea whose definition relies upon a particular context. The accomplishment of project objectives requires proficient project control (Nieminen \& Lehtonen, 2008). A handful of components among the set of the successful actors of industry are critical to such an extent that a firm might be compelled to leave the business and lose the opposition in the event of not giving adequate consideration to those (Thompson, 2005; Ketelhohn, 1998). In reality, one of the basic exercises in arranging and strategic management is the identification of $\mathrm{KSF}^{1}$ toward which proper reaction ought to be considered (Thompson 2005, Grant 2010). The most significant resource of an association and its powerful administration is the way to the success of the organization (Liisa, et al.2012). HR is the most significant input to a system. (Yeo, 1995).HR indicates, and without a doubt will show likewise in the near future, the best possible upper hand of organizations. The state of the appearance of this prerequisite is a successful administration of HR, for example useful arranging, sorting out, driving and controlling (Samolejova et al., 2015). Projects should turn into a progressively focal worry of HRM researchers, not least since representatives and supervisors, just as the individuals who speak to them, are regularly drawn from these settings. The review can give a beginning stage to such examinations to advance the HRM field and further reinforce the field of project management (keegan et al.,2017). Huemann et al. (2007) research on human resource management in project-oriented structure has been conducted, and they have examined the important aspects of human resource management in project organization (Huemann et al., 2007). Moreover, in 2016, Becker and Smith conducted research on the risks posed by inappropriate human resource management practices and stated human resource management as a discipline plays a significant duty in enhancing human resource awareness as a threat to the organization (Becker \& Smith, 2016).

\footnotetext{
${ }^{1}$ Key success factor
} 
Lila Carden and et.al also in their review research; expressed information about the identification, classification, and management of project human resources (Lila Carden et al., 2019). MCDM instruments have been the most usually used expository methodologies since the idea of organizing the KSF in HRM is fairly mind-boggling and multi-faceted. MCDM procedures allude to strategies give requesting or grouping of choices and settle on a decision among them by assessment of numerous choice models (Sengul et al., 2015). MCDM approach has all earmarks of being the most suitable technique to manage convoluted hazard factors in different viewpoints, including political, monetary, social, and specialized, and process the general hazard assessment of doable other options. Lately, an expanding number of studies concerns the MCDM procedures, for example, Elimination and Choice Expressing Reality (ELECTRE) (Zhou Huan et al., 2017), Preference Ranking Organization Method for Enrichment Evaluation (PROMETHEE) (Liang et al., 2017), dark methodology (Liu et al., 2017; Su et al., 2016), etc. These strategies can successfully tackle MCDM issues from various points (Wang et al., 2018). TOPSIS as one of the most relevant MCDM strategies relegates the best option among numerous practical options by figuring the good ways from the positive perfect and the negative ideal (anti-ideal) arrangements (Mahdevari et al., 2014), and it's ordinarily applied in taking care of MCDM issues (Lima Junior et al., 2014; Onu et al., 2017; Sengul et al., 2015).ANP is an improved increasingly expressive variant of the AHP technique as it permits criticism between the layers and obliges association among criteria (Kababk et al., 2014). Hence, this investigation uses an MCDM strategy (ANP) to decide the significance loads of assessment measures and TOPSIS to get the presentation appraisals of the achievable choices in values defined with numbers. This methodology is utilized for four reasons:

(a) TOPSIS rationale is balanced and justifiable; (b) the calculation forms are direct; (c) the idea allows the quest for best choices for every measure delineated in a basic numerical structure, and (d) the significance loads are joined into the correlation strategies (Wang and Chang, 2007).

\section{Materials and methods}

\subsection{Research methodology}

In fact, research methods are tools to achieve reality. In any research, the researcher tries to choose the most appropriate method, and that's the way to discover more accurately the rules and facts than other methods. Therefore, choosing the right research method to require understanding existing fact and the relationships. In this research, for pervious research from library studies used in the field of human resource management development projects. The main purpose of this research, identifying and prioritization of critical success factors in human resource management development project through extraction from previous source and review and experts' changes. After identifying the factor, the factors were categorized due to importance by designing and distributing a questionnaire among the experts of the Isfahan subway construction project contractor. With the initial screen of predetermined factors by SPSS software and Friedman statistical test of the 27 factorsSelected 7 factors that were more important for experts. Eventually, selected and prioritized the factors with two multi-criteria decision-making methods:

1- Using ANP method

2- Applying TOPSIS method

\subsection{Exploration and prioritization of factors}

The main purpose of this research is the Identification and Prioritization of Critical Success Factors in Human Resource Management in the Isfahan Metro Construction Project. To achieve this goal, after reviewing comprehensive literature and interviewing experts, 27 factors were extracted and reviewed by experienced experts. These factors are categorized into 7 groups based on the review of previous literature. Key Success Factors in Human Resource Management in Development Projects:

Table 1

Construction project valuation key success factor variable

\begin{tabular}{ccl}
\hline Group & Variable & \multicolumn{1}{c}{ Key Success Factors in Human Resource Management } \\
\hline Organization & $A_{1}$ & Select project manager and project team with high management skills \\
& $A_{2}$ & $\begin{array}{l}\text { Support the management of the project team and Feeling worthy of people in the project team } \\
\text { Appropriate Expectation of Employees by manager and Proper job design }\end{array}$ \\
& $A_{3}$ & $\begin{array}{l}\text { Creating a common vision and alignment in personal and organizational perspectives Completion time and } \\
\text { future of the project (Determine the goals of the project) }\end{array}$ \\
\hline Business relationships & $A_{5}$ & Having effective and comprehensive communication between project team members \\
& $A_{6}$ & Increasing trust and confidence between employees and project team managers \\
& $A_{7}$ & Change the communication pattern Between different project managers and employees \\
& $A_{8}$ & $\begin{array}{l}\text { Allowing new ideas to be expressed and implemented and Prevalence of Tolerance and being critical Be- } \\
\text { tween project managers and staff }\end{array}$ \\
\hline Supply of resources & $A_{9}$ & Providing credit resources Financial is safe and sufficient \\
& $A_{10}$ & Institutionalizing creativity and innovation and Access to modern technologies \\
& $A_{11}$ & Allocation of sufficient resources to Support for creativity and innovation of the organization \\
& $A_{12}$ & Employment powerful employees as human resources \\
\hline
\end{tabular}


Table 1

Construction project valuation key success factor variable (Continued)

\begin{tabular}{cll}
\hline $\begin{array}{c}\text { Performance manage- } \\
\text { ment }\end{array}$ & $A_{13}$ & Analysis of opportunities and threats to the environment in relation to human \\
& $A_{14}$ & Valuable questioning and Undertaking the current situation and Challenging project workplaces \\
& $A_{15}$ & Gaining employee support and Creating a sense of responsibility in them \\
Human recourse devel- & $A_{16}$ & Supporting learners for change and innovation by creating a flexible space \\
opment & $A_{17}$ & There will be continuous Ability to develop skills in the project team and Skills update. \\
& $A_{18}$ & Preparing People in full partnership in the information through the transfer of knowledge to others \\
& $A_{19}$ & Staff Capabilities to make decisions \\
\hline Reward Management & $A_{20}$ & Training learning power in individuals \\
\hline Staff relations & $A_{21}$ & Periodic rewards Subject to Timely completion of the project based on timing as an incentive to raise individ- \\
& $A_{22}$ & Compensation policies based on team project results \\
& $A_{23}$ & Creating job security in the field of safety and health of project staff \\
\hline$A_{24}$ & Encouraging teamwork and Solving problem group \\
& $A_{25}$ & Transfer of individual experiences between project team members \\
& $A_{26}$ & Existence Feeling pleasure and informality Between project team members at work \\
& $A_{27}$ & Increase the spirit of cooperation among members of the project team \\
\hline
\end{tabular}

A questionnaire was designed to collect expert opinions at Metro Isfahan Developmental Project Contract or Company on the importance of each factor, and it was distributed among 47 members of the community. Collected data were analyzed through the questionnaire using statistical software. To determine Critical Success Factors for HRM in the Metro Project of Isfahan among the primary factors using Friedman's statistical test and using SPSS statistical software, the factors that matter to them from the statistical point of view are meaningful were determined .Due to the results of these tests, the number of 7 factors were selected in this level.

\subsection{Freedman test}

Table 2 shows average ratings of each of the influential variables on the success of the Metro development project based on Friedman's test. The Friedman test is the non-parametric option in contrast to the single direction ANOVA with repeated measures. It is utilized to test for contrasts among bunches when the needy variable being estimated is ordinal. It can likewise be utilized for persistent information which has abused the suppositions important to run the single direction ANOVA with rehashed measures.

Table 2

Friedman test result

\begin{tabular}{ccl}
\hline Ranking & Average rating & \\
\hline $\mathbf{1}$ & 20.56 & Providing credit resources Financial is safe and sufficient \\
$\mathbf{1}$ & 20.56 & Creating job security in the field of safety and health of project staff \\
$\mathbf{2}$ & 20.14 & Select project manager and project team with high management skills \\
$\mathbf{3}$ & 20.14 & Support the management of the project team and Feeling worthy of people in the project team \\
$\mathbf{4}$ & 18.30 & Analysis of opportunities and threats to the environment in relation to human resources \\
& 17.76 & $\begin{array}{l}\text { Periodic rewards Subject to Timely completion of the project based on timing as an incentive to raise in- } \\
\text { dividual motivations }\end{array}$ \\
$\mathbf{5}$ & 17.54 & $A_{23}$ \\
\hline
\end{tabular}

Due to the table and Check Friedman test ranking, 7 factors were chosen which were more important (Table 2). In the following, considering the Multi-criteria nature of this assessment, using Multi-criteria techniques ANP and TOPSIS as the next step of this research selected for more reliable results.

\subsection{ANP method}

The ideas and techniques for Multi-Criteria Decision Making present a system that fuses various, clashing models into arranging (Ghajar \& Najafi, 2012). Issues with feedback and intangibles in MCDM can be tended to by decision-making methods, for example, the Analytic Network Process. The ANP model contains three components, (1) objective of choosing the best other option, (2) criteria and sub-criteria for the model, and (3) options. The components in the chain of command of determinants are partitioned into measurements and property empowering agents. Recognizable proof of measurements and property empowering influences at each level and definition of inter connections are essential for the advancement of the decision model. The target of order is at last to find out the other alternatives (Najafinasab et al., 2015). For appropriate pairwise correlation of matrices, the assessment of specialists was gathered utilizing a nine-point scale as recorded (Table 3). The number of matrices relies upon the quantity of components at each level, and the request for the network at each level relies upon the number of components at the lower level to which it is connected. The pair-wise examinations are made as far as how the component is a higher priority than component B. It utilizes a proportion scale for each degree of measures, submodels, and options, which permits the development of relative weight matrices (Sakthivel et al., 2015). For instance, for a 
given basis in the primary column, in the event that option A is "Firmly Preferred" over option B, at that point, a load of 7 is entered. If option A is "Emphatically Preferred" over elective C, at that point a load of 5 is entered. The judgment matrix A where each element $a_{i j}(\mathrm{i}, \mathrm{j}=1,2, \ldots, \mathrm{n})$ is the remainder of loads of the measures, as appeared:

$$
A=\left(\begin{array}{cccc}
a_{11} & a_{12} & \cdots & a_{1 n} \\
a_{21} & a_{22} & \cdots & a_{2 n} \\
\vdots & \vdots & \ddots & \vdots \\
a_{31} & a_{32} & \cdots & a_{3 n}
\end{array}\right), a_{i i}=1, a_{i i}=1 / a_{i j}, a_{i j} \neq 0
$$

The decision matrix for the ideal mix determination is figured by distinguished criteria and choices utilizing Eq. (1). At the last advance, the mathematical procedure is started to normalize and locate the general loads of every network. The relative loads are given by the right Eigenvector $(w)$ comparing to the biggest Eigen value $\left(\lambda_{\max }\right)$, as

$$
A_{w}=\lambda_{\max } w
$$

If the pair-wise examinations are totally predictable, the matrix A has rank 1. For this situation, loads can be gotten by normalizing any of the lines or sections of A (Wang \& Yang, 2007). It ought to be noticed that the nature of yield of ANP is carefully identified with the consistency of pair insightful correlation decisions. The consistency is characterized by the connection among the sections of $\mathrm{A}$ :

$a_{i j} \times a_{j k}=a_{i k}$. The Consistency Index (CI) is

$$
C I=\left(\lambda_{\max }-n /(n-1)\right.
$$

The last consistency ratio (CR), utilization of which let somebody close whether the assessments are adequately predictable, is determined as the ratio of the CI and the random index (RI), as showed.

$$
C R=C I / R I
$$

where RI is the normal record for haphazardly created loads. The number 0.1 is the accepted upper limit for CR. If the last consistency proportion surpasses this worth, the assessment technique should be repeated to improve consistency. The estimation of consistency can be utilized to assess the consistency of decision-makers just as the consistency of overall hierarchy (Dagdeviren et al., 2009).

Table 3

Relative significance (weight) scales for pair wise comparison

\begin{tabular}{lll}
\hline Value & Significance & Explanation \\
\hline $\mathbf{1}$ & Equal importance & Two activities are equally important or do not take precedence over each other \\
$\mathbf{3}$ & poor importance & Given the slight superiority of one activity over another \\
$\mathbf{5}$ & Strong importance & Due to great superiority of one activity over another \\
$\mathbf{7}$ & Very strong importance & One activity is much more important than another \\
$\mathbf{9}$ & Absolute or extreme importance & Evidence, shows the tremendous importance of one activity over another \\
$\mathbf{2 , 4 , 6 , 8}$ & Intermediate values & Shows intermediate values \\
\hline
\end{tabular}

\subsection{TOPSIS method}

The TOPSIS is generally utilized for handling positioning issues in genuine circumstances. This technique is regularly reprimanded for its powerlessness to sufficiently deal with the inborn vulnerability and imprecision related to the planning of the leader's observation to fresh qualities. In the customary detailing of the TOPSIS, individual decisions are indicated with fresh values (Amiri, 2010). Hence, in numerous down to earth cases, the human inclination model is unsure, and leaders may be hesitant or incapable to allocate fresh qualities to the examination decisions. (Chan \& Kumar, 2007; Shyur \& Shih, 2006). The TOPSIS (method for request execution by likeness to perfect arrangement) was first evolved by Hwang and Yoon (1981). As per this strategy, the best option would be the one that is closest to the positive-ideal arrangement and farthest from the perfect negative arrangement (Ertugrul \& Karakasoglu, 2007). The positive-ideal arrangement is an answer that boosts the advantage measures and limits the cost criteria, though the perfect negative arrangement amplifies the cost models and limits the advantage rules (Wang \& Elhag, 2006). To put it plainly, the positive-perfect arrangement is made out of every single best worth achievable from the criteria, though the perfect negative arrangement comprises of every most noticeably awful worth feasible from the rules (Wang, 2007). There have been bunches of studies in writing utilizing TOPSIS for the arrangement of MCDM issues (Chu \& Lin, 2002; Dagdeviren et al., 2009; Wang et al., 2005). The TOPSIS procedure incorporates the means as follows:

1) Calculating the normalized decision matrix. The normalized value $r_{i j}$ is determined as 
$r_{i j=} f_{i j} / \sqrt{\sum_{j=1}^{J} f_{i j}^{2}}, j=1, \ldots, n ; i=1, \ldots, n$

2) Calculating the weighted normalized decision matrix. The weighted normalized value $v_{i j}$ is gotten as

$v_{i j}=\mid w_{i} r_{i j}, \quad j=1, \ldots, J ; i=1, \ldots, n$

Where $w_{i}$ is the weight of the criterion, and $\sum_{i=1}^{n} w_{i}=1$.

3) Characterizing the perfect and negative-ideal arrangement.

$$
\begin{aligned}
& A^{*}=\left\{v_{1}^{*}, \ldots, v_{n}^{*}\right\}=\left\{\left(\max _{j} v_{i j} \mid i \in I^{\prime}\right),\left(\min _{j} v_{i j} \mid i \in I^{\prime \prime}\right)\right\}, \\
& A^{-1}=\left\{v_{1}^{-}, \ldots, v_{n}^{-}\right\}=\left\{\left({ }_{j}^{\min } v_{i j} \mid i \in I^{\prime}\right),\left(\max _{j} v_{i j} \mid i \in I^{\prime \prime}\right)\right\},
\end{aligned}
$$

Where I' is identified with advantage criteria, and I" is identified with cost criteria.

4) Registering the separation measures by the utilization of n-dimensional Euclidean separation. The detachment of each substitute from the perfect arrangement is determined as

$$
D_{j}^{*}=\sqrt{\sum_{i=1}^{n}\left(v_{i j}-v_{i}^{*}\right)^{2}}, j=1, \ldots, J
$$

So, the separation from the perfect negative arrangement is indicated.

$$
D_{j}^{-}=\sqrt{\sum_{i=1}^{n}\left(v_{i j}-v_{i}^{-}\right)^{2}}, j=1, \ldots, J
$$

5) Processing the relative closeness to the perfect arrangement. The overall closeness of alternative $a_{j}$ with

$$
C_{\mathrm{j}}^{*}=\mathrm{D}_{\mathrm{j}}^{-} /\left(\mathrm{D}_{\mathrm{j}}^{+}+\mathrm{D}_{\mathrm{j}}^{-}\right), \mathrm{j}=1, \ldots, \mathrm{J}
$$

6) Rank the inclination request. Select an option with most extreme $C C_{i}$ or rank alternatives as per $C C_{i}$ in descending request.

\subsection{The suggested method}

The suggested model for recognizing and prioritization of Critical Success Factors in Human Resource Management, made out of ANP and TOPSIS strategies, comprises of three essential stages: (1) Recognizing the rules to be utilized in the model, (2) ANP calculations, (3) Assessment of choices with TOPSIS and assurance of the last rank. In the main stage, elective Critical Success Factors in Human Resource Management and the models which will be utilized in their assessment are resolved, and the choice chain of command and system is shaped. ANP model is organized with the end goal that the goal is in the main level, rules are in the subsequent level and elective Success Factors in Human Resource Management are on the third level. In the last advance of the principal stage, the choice chain of importance and system is affirmed by the decision-making team. After the approval of decision hierarchy and network, rules utilized in prioritization of Critical Success Factors in Human Resource Management determination are appointed loads utilizing ANP. In this stage, pair-wise examination networks are framed to decide the measures loads. The specialists from decision- making team make singular assessments utilizing the scale gave in(Table 3), to decide the estimations of the components of pair-wise comparison matrices (Dagdeviren et al., 2009). . Processing the geometric mean of the qualities acquired from singular assessments, thelast pair-wise correlation framework on which there is an accord is found. The loads of the criteria are determined dependent on this last examination network. In the last advance of this stage, determined loads of the criteria are affirmed by decision-making team. Basic Success Factors in Human Resource Management in project positions are controlled by utilizing the TOPSIS strategy in the third stage. The success factors having the greatest $C C_{i}$ value is resolved as the ideal success factors as per the counts by the TOPSIS. Positioning of different achievement factors is resolved by $C C_{i}$ in descending order. A schematic graph of the suggested model for critical success factors determination is prepared (Fig. 1). 
Developing the research ANP model

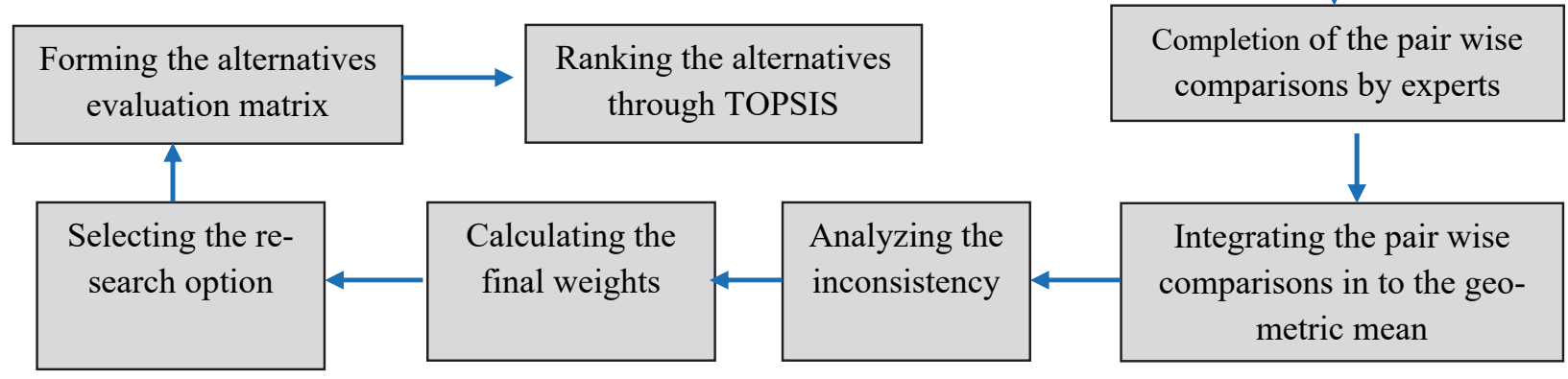

Fig. 1. Frame work proposed Research process

\section{Results and discussion}

The fundamental target of investigation is to survey potential ways and give a few models to help the chiefs organize Critical Success Factors in Human Resource Management in the construction project. Organizing the most legitimate Critical Success Factors in Human Resource Management is vital for projects. The application, a specialist group, was framed from various specialists in the project management field, project administrators, metro project, and the creators of this paper. The rules to be utilized in the model were dictated by the master group. Pairwise correlation grids used to figure measure loads were additionally framed by a similar group. The application performed depends on the means given in the past area and clarified bit by bit along with the outcomes.

\subsection{Identification of criteria}

Taking into account that Human Resource Management use as one of the significant utilization of project management development approaches in development project's Iran, has been created. Criteria to be considered in the determination of basic achievement factor are controlled by the master group. Past investigation, past experience and the foundation of the master group are used in the assurance of the criteria and 27 significant choices to be utilized for distinguishing basic achievement factors in humans. Following the assurance of the rules, proposed electives considered and chosen, the chief group recommended 7 fitting other alternatives. Criteria to be considered in organizing the critical success of human plan management in projects are controlled by the master group from the Construction Company. These three criteria are as per the following; Time (C1), Cost (C2), Quality (C3). Therefore, just these three models were utilized to assess and choose the chain of command as needs are. A choice system organized with the decided option critical success components and criteria is given (See Fig 2). There are three levels in the decision hierarchy order and system organized for critical success factors in human asset the executives in development projects. The general objective of choice procedure decided as "recognize and prioritization of critical success factors in human assets by the executives" is in the main degree of order. The measures are on the subsequent level and option critical success factors in HRM are on the third degree of order in the network. As shown, a reliance relationship exists among assessment measures for distinguishing and prioritization of basic achievement factors in human resource management.

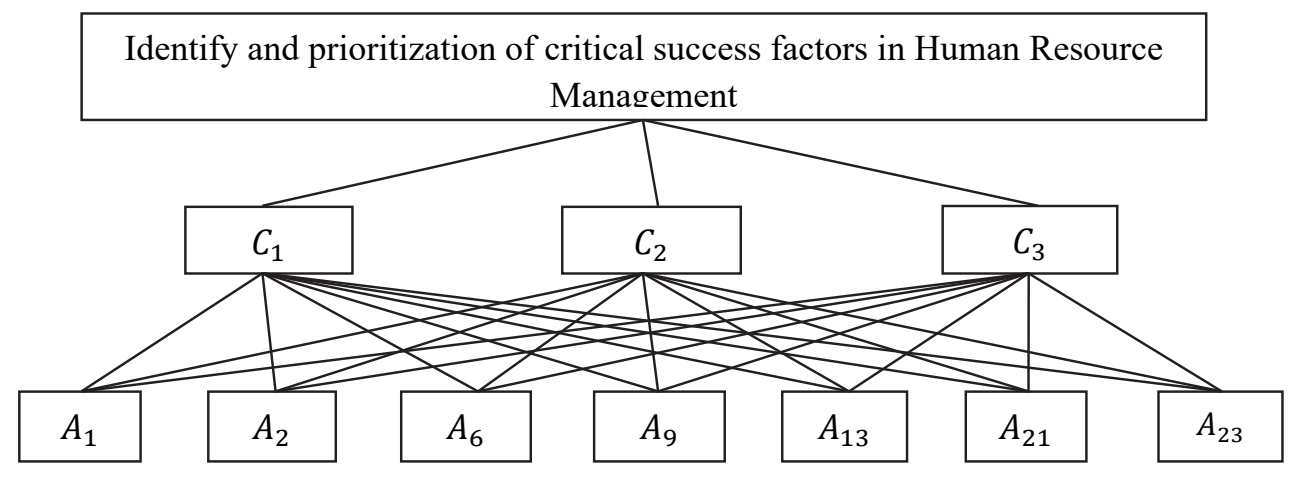

Fig. 2. The decision hierarchy structure in network 


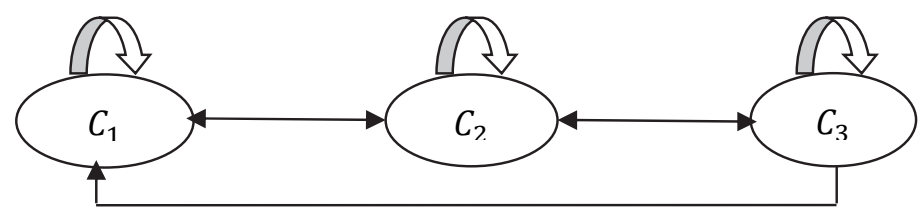

Fig. 3. The affiliation communication among evaluation criteria.

\subsection{The weights of the criteria}

After forming the progressive choice system in the network for the choice of the significant factor of human resource management in the construction project, the loads of criteria to be utilized in the assessment process are determined using the ANP technique (Wu et al., 2010). In this stage, the specialists in the master group are given the task of forming an individual pairwise examination network in ANP by utilizing the scale given (Table 3). The outcomes acquired from the calculations dependent on the pair wise comparison matrix in ANP gave in Table 4. The $C_{2}$ are resolved as the most significant criteria in the metro project process by ANP (Table5). The consistency proportion of pairwise comparison matrix is determined as $<0.1$. So, the loads are indicated to be reliable, and they are utilized in the choice procedure.

Table 4

The final matrix of ANP results

\begin{tabular}{|c|c|c|c|c|c|c|c|c|c|c|c|}
\hline & Goal & Quality & Cost & Time & $V_{9}$ & $\mathbf{V}_{23}$ & $V_{1}$ & $\mathbf{V}_{2}$ & $V_{13}$ & $V_{21}$ & $V_{6}$ \\
\hline Quality & 0.306 & 0 & 0 & 0 & 0.305372 & 0.306867 & 0.306707 & 0.306796 & 0.307498 & 0.30714 & 0.306527 \\
\hline Cost & 0.368 & 0 & 0 & 0 & 0.366767 & 0.368555 & 0.368335 & 0.368422 & 0.369287 & 0.368842 & 0.368157 \\
\hline Time & 0.316 & 0 & 0 & 0 & 0.318599 & 0.316754 & 0.315228 & 0.315884 & 0.315552 & 0.315288 & 0.316525 \\
\hline$V_{9}$ & 0.099 & 0.09983 & 0.10031 & 0.099214 & 0 & 0 & 0 & 0 & 0 & 0 & 0 \\
\hline$V_{23}$ & 0.177 & 0.177394 & 0.17787 & 0.177072 & 0 & 0 & 0 & 0 & 0 & 0 & 0 \\
\hline$V_{1}$ & 0.033 & 0.03322 & 0.033254 & 0.033294 & 0 & 0 & 0 & 0 & 0 & 0 & 0 \\
\hline $\mathbf{V}_{2}$ & 0.056 & 0.056369 & 0.056462 & 0.05642 & 0 & 0 & 0 & 0 & 0 & 0 & 0 \\
\hline$V_{13}$ & 0.19 & 0.190033 & 0.190098 & 0.19073 & 0 & 0 & 0 & 0 & 0 & 0 & 0 \\
\hline$V_{21}$ & 0.193 & 0.192864 & 0.192921 & 0.193609 & 0 & 0 & 0 & 0 & 0 & 0 & 0 \\
\hline$V_{6}$ & 0.238 & 0.238515 & 0.239198 & 0.237961 & 0 & 0 & 0 & 0 & 0 & 0 & 0 \\
\hline
\end{tabular}

Table 5

The ultimate weights of the basic criteria

\begin{tabular}{cccc}
\hline Criteria & & Weight & Rank \\
\hline Quality & $C_{1}$ & 0.306 \\
Cost & $C_{2}$ & 0.368 & 3 \\
Time & $C_{3}$ & 0.316 & 1 \\
\hline
\end{tabular}

\subsection{Valuation, of alternatives and specify the ultimate rank}

At this phase of the choice strategy, the colleagues were approached to build up the choice network by looking at choices under every one of the rules independently. The decision matrix was normalized utilizing Eq. (5). The decision matrix was normalized. At last, every section was isolated by the base of the complete total of squares of the passages. (Table 6) in the segment presents the normalized matrix. This progression, the normal matrix is weighted. In outline, the weights coming about because of the ANP method are increased by the normal matrix so as to acquire a weighted matrix (Table 7).

Table 6

TOPSIS normal matrix

\begin{tabular}{cccc}
\hline & $\boldsymbol{C}_{\mathbf{1}}$ & $\boldsymbol{C}_{\mathbf{2}}$ & \\
$\boldsymbol{V}_{\mathbf{9}}$ & 0.238018 & 0.238722 & \\
$\boldsymbol{V}_{\mathbf{2 3}}$ & 0.42295 & 0.423303 & 0.236508 \\
$\boldsymbol{V}_{\mathbf{1}}$ & 0.079205 & 0.079138 & 0.422106 \\
$\boldsymbol{V}_{2}$ & 0.134398 & 0.13437 & 0.079366 \\
$\boldsymbol{V}_{\mathbf{1 3}}$ & 0.453084 & 0.452402 & 0.134494 \\
$\boldsymbol{V}_{\mathbf{2 1}}$ & 0.459834 & 0.45912 & 0.454665 \\
$\boldsymbol{V}_{\mathbf{6}}$ & 0.568676 & 0.569253 & 0.461527 \\
\hline
\end{tabular}

The positive and negative beliefs are recognized in this area. The positive perfect for the positive criteria rises to the biggest passage for every basis in the segment of the weighted matrix, while the perfect negative equivalents the littlest section for every measure in the segment of the weighted matrix. The positive and negative standards are likewise conversely distinguished for the negative models, as appeared in (Table 8). The Euclidean distance of alternatives from the positive and negative beliefs is acquired for this reason. 
Table 7

The TOPSIS weighted matrix

\begin{tabular}{ccccc}
\hline & $\boldsymbol{C}_{\mathbf{1}}$ & $\boldsymbol{C}_{\mathbf{2}}$ & \\
\hline $\boldsymbol{V}_{\mathbf{9}}$ & 0.072833 & 0.08785 & 0.074737 \\
$\boldsymbol{V}_{\mathbf{2 3}}$ & 0.129423 & 0.155775 & 0.133386 \\
$\boldsymbol{V}_{\mathbf{1}}$ & 0.024237 & 0.029123 & 0.02508 \\
$\boldsymbol{V}_{2}$ & 0.041126 & 0.049448 & 0.0425 & 0.143674 \\
$\boldsymbol{V}_{\mathbf{1 3}}$ & 0.138644 & 0.166484 & 0.145842 \\
$\boldsymbol{V}_{\mathbf{2 1}}$ & 0.140709 & 0.168956 & 0.179252 \\
$\boldsymbol{V}_{\mathbf{6}}$ & 0.174015 & 0.209485 & \\
\hline
\end{tabular}

Table 8

The TOPSIS positive and negative ideals

\begin{tabular}{ccccc}
\hline & $\boldsymbol{C}_{\mathbf{1}}$ & $\boldsymbol{C}_{\mathbf{2}}$ & $\boldsymbol{C}_{\mathbf{3}}$ & \\
\hline $\boldsymbol{A}^{+}$ & 0.174015 & 0.029123 & 0.179252 \\
$\boldsymbol{A}^{-}$ & 0.024237 & 0.209485 & 0.02508 & \\
\hline
\end{tabular}

In this stage, the likeness list is determined for every alternative by isolating the perfect negative separation by the absolutely positive and negative perfect. The sub-rules are determined regarding the subsequent value (Yung et al., 2003). Last, the outcomes are recorded in the fourth and fifth sections (Table 9), respectively.

Table 9

The resemblance indicator and the distance from the ideals in TOPSIS

\begin{tabular}{|c|c|c|c|c|}
\hline & Rank & $C_{i}$ & $D^{-}$ & $\boldsymbol{D}^{+}$ \\
\hline$A_{9}$ & 5 & 0.471722 & 0.140081 & 0.156876 \\
\hline$A_{23}$ & 4 & 0.530376 & 0.160247 & 0.141891 \\
\hline$A_{1}$ & 7 & 0.456256 & 0.180362 & 0.214948 \\
\hline$A_{2}$ & 6 & 0.457726 & 0.161866 & 0.1917065 \\
\hline$A_{13}$ & 3 & 0.538014 & 0.170302 & 0.146236 \\
\hline$A_{21}$ & 2 & 0.539083 & 0.172604 & 0.147577 \\
\hline$A_{6}$ & 1 & 0.547444 & 0.214948 & 0.180362 \\
\hline
\end{tabular}

The data analysis suggests that after recognizing the measures, building up the ANP organize model, and getting the last loads of the standards, it was discovered that the cost, time; quality reached the first to third positions among the criteria, regarding their impact on project success dependent on their loads. Among the measures impacting the project success of the development project, the expense was recognized as the most compelling model among other 2 criteria affecting the elements, recommending that the task can be performed by the timetable through ideal cost. Time is ranked second as an influence factor by other project factors. Time after the cost was selected as the most effective parameter. In the next stage of decision-making, the experts were asked to determine the decision matrix by comparing other options under each of the criteria. The second step after determining the evaluation matrix is to acquire the weight decision table. The conclusions of TOPSIS analyses are summarized in Table 9. Based on $C_{i}$ values, the ranking of the alternatives indescending order are $A_{6}, A_{21}, A_{13}, A_{23}, A_{9}, A_{2}$ and $A_{1}$ proposed model results indicate that $A_{6}$, is the best alternative with $C_{i}$ value of 0.547 .

\section{Conclusion and suggestions}

In this examination, a blend of the hierarchical methods was utilized for analyzing Success Factors in Human Resource Management of metro projects in Iran. These deciding components were investigated as 3 fundamental rules cost, time, and quality. Subsequent to breaking down the 3 standards that cost was chosen as the most powerful measure, while the time model was recognized as the most susceptible quality criterion. Taking into account that human resource management is used as one of the significant employments of project success in Iran was created. Moreover, it ought to be given models so as to choose an appropriate factor. Due to the conclusions obtained in this study utilization a combined ANP, TOPSIS method, alternative $\mathrm{A}_{6}$, increasing trust and confidence between employees and project team managers, was selected from among factors as the most important factor. Moreover, option $\mathrm{A}_{1}$, select project manager and project team with high management skills got the lowest score and ranking among the choices introduced. In this research, a decision model was provided for key Success Factors in Human Resource Management. A decision model accommodated key Success Factors in Human Resource Management. As per the recognized measures, the proposed model depends on the correlations of key Success Factors alternatives in the project. ANP and TOPSIS compound dynamic strategy was utilized in the proposed model. ANP is used to dole out loads to the measures to be utilized in key achievement factors in venture determination, while TOPSIS is utilized to decide the needs of the other alternatives. The weights obtained from ANP are remembered for the dynamic procedure using them in TOPSIS calculations, and the elective needs are resolved dependent on these weights. Along these lines, the weighting of the models considered during decision-making and assessment of these criteria is done simultaneously. In prioritizing key success factors, 
the proposed model has fundamentally expanded the effectiveness of the decision-making procedure. TOPSIS helped in reaching an inference inside a brief timeframe. Moreover, in the application, it was uncovered that the count of criteria weights is significant in TOPSIS strategy and they could change the positioning. In spite of the fact that this model is upgraded for selecting key Success Factors in Human Resource Management of the metro project, specialists are encouraged to utilize the calculation to recognize and assess the significant elements in the tasks and using present day logical strategies, for example, blend of ANP and TOPSIS and help supervisors and leaders in significant national choices. Numerical models can likewise be joined with the recommended model. This mix can assist with improving and can likewise be one of the things to research headings in various points.

Management thinkers believe that the future challenge of managers is not technology and information, the future challenge is human resource managers and the ones who develop talent and then absorb. It has aspired that the conclusions of this paper will have an affirmative impact on the success of development projects.

\section{References}

Acharya, V., Pagano, M., \& Volpin, P. (2016). Seeking alpha: Excess risk taking and competition for managerial talent. The Review of Financial Studies, 29(10), 2565-2599.

Ahsan, K., Ho, M., \& Khan, S. (2013). Recruiting project managers: A comparative analysis of competencies and recruitment signals from job advertisements. Project Management Journal, 44(5), 36-54.

Hoseini, M.Yazdi, H. Yazdi, M. (2015). Identifying and prioritizing key success factors of construction projects with AHP technique (A case study of Shiraz Contractor Company). 3rd International Conference on Applied Research in Civil Engineering, Architecture and Urban Management, Iran.

Amiri, M. P. (2010). Project selection for oil-fields development by using the AHP and fuzzy TOPSIS methods. Expert systems with applications, 37(9), 6218-6224.

Ammeter, A. P., \& Dukerich, J. M. (2002). Leadership, team building, and team member characteristics in high performance project teams. Engineering management journal, 14(4), 3-10.

Becker, K., \& Smidt, M. (2016). A risk perspective on human resource management: A review and directions for future research. Human Resource Management Review, 26(2), 149-165.

Belassi, W., \& Tukel, O. I. (1996). A new framework for determining critical success/failure factors in projects. International journal of project management, 14(3), 141-151.

Bossink, B. A. (2004). Effectiveness of innovation leadership styles: a manager's influence on ecological innovation in construction projects. Construction Innovation, 4(4), 211-228.

Carden, L., Kovach, J. V., \& Flores, M. (2020). Enhancing human resource management in process improvement projects. Organizational Dynamics, 100776.

Chan, F. T., \& Kumar, N. (2007). Global supplier development considering risk factors using fuzzy extended AHP-based approach. Omega, 35(4), 417-431.

Chang, R. D., Soebarto, V., Zhao, Z. Y., \& Zillante, G. (2016). Facilitating the transition to sustainable construction: China's policies. Journal of Cleaner Production, 131, 534-544.

Cheng, M. I., Dainty, A. R., \& Moore, D. R. (2005). What makes a good project manager?. Human resource management journal, 15(1), 25-37.

Chu, T. C., \& Lin, Y. C. (2002). Improved extensions of the TOPSIS for group decisionmaking under fuzzy environment. Journal of Information and Optimization Sciences, 23(2), 273-286.

Cooke-Davies, T. (2002). The "real" success factors on projects. International journal of project management, 20(3), 185190.

Crawford, L. (2000, June). Profiling the competent project manager. In Proceedings of PMI Research Conference (pp. 3-15). Newton Square, PA: Project Management Institute.

Dağdeviren, M., Yavuz, S., \& Kılınç, N. (2009). Weapon selection using the AHP and TOPSIS methods under fuzzy environment. Expert systems with applications, 36(4), 8143-8151.

Dolfi, J., \& Andrews, E. J. (2007). The subliminal characteristics of project managers: An exploratory study of optimism overcoming challenge in the project management work environment. International Journal of Project Management, 25(7), 674-682.

Elkhalifa, A. (2016). The magnitude of barriers facing the development of the construction and building materials industries in developing countries, with special reference to Sudan in Africa. Habitat International, 54, 189-198.

Ertuğrul, İ., \& Karakaşoğlu, N. (2009). Performance evaluation of Turkish cement firms with fuzzy analytic hierarchy process and TOPSIS methods. Expert Systems with Applications, 36(1), 702-715.

Gan, X., Zuo, J., Ye, K., Skitmore, M., \& Xiong, B. (2015). Why sustainable construction? Why not? An owner's perspective. Habitat International, 47, 61-68.

Ghajar, I., \& Najafi, A. (2012). Evaluation of harvesting methods for sustainable forest management (SFM) using the analytical network process (ANP). Forest Policy and Economics, 21, 81-91.

Ghoddousi, P., \& Hosseini, M. R. (2012). A survey of the factors affecting the productivity of construction projects in Iran. Technological and economic development of economy, 18(1), 99-116. 
Giannetti, M. (2011). Serial CEO incentives and the structure of managerial contracts. Journal of Financial Intermediation, 20(4), 633-662.

Grant, R. M. (2016). Contemporary strategy analysis: Text and cases edition. John Wiley \& Sons.

Hafezi, F., Faezi, F. (2015). The impact of strategic human resource management on the success of development projects. The first international management conference in the 21 st century, Iran.

Huemann, M., Keegan, A., \& Turner, J. R. (2007). Human resource management in the project-oriented company: A review. International journal of project management, 25(3), 315-323.

Hwang, C.L., Yoon, K. (1981). Multiple Attribute Decision Making: Methods and Applications, a State of the Art Survey. Springer-Verlag, New York.

Ika, L. A. (2009). Project success as a topic in project management journals. Project management journal, 40(4), 6-19.

Ika, L. A., \& Hodgson, D. (2014). Learning from international development projects: blending critical project studies and critical development studies. International Journal of Project Management, 32(7), 1182-1196.

Nijkerk. (2006). International Project Management Association, ICB - IPMA Competence Baseline, 3Rd edition, International Project Management Association.

Kabak, M., \& Dağdeviren, M. (2014). Prioritization of renewable energy sources for Turkey by using a hybrid MCDM methodology. Energy Conversion and Management, 79, 25-33.

Keegan, A., Ringhofer, C., \& Huemann, M. (2018). Human resource management and project based organizing: Fertile ground, missed opportunities and prospects for closer connections. International Journal of Project Management, 36(1), 121-133.

Ketelhöhn, W. (1998). What is a key success factor?. European Management Journal, 16(3), 335-340.

Lehtonen, P., \& Martinsuo, M. (2006). Three ways to fail in project management and the role of project management methodology. Project Perspectives, 28(1), 6-11.

Liang, R. X., Wang, J. Q., \& Zhang, H. Y. (2018). Projection-based PROMETHEE methods based on hesitant fuzzy linguistic term sets. International Journal of Fuzzy Systems, 20(7), 2161-2174.

Lehtiranta, L., Kärnä, S., Junnonen, J. M., \& Julin, P. (2012). The role of multi-firm satisfaction in construction project success. Construction Management and Economics, 30(6), 463-475.

Junior, F. R. L., Osiro, L., \& Carpinetti, L. C. R. (2014). A comparison between Fuzzy AHP and Fuzzy TOPSIS methods to supplier selection. Applied Soft Computing, 21, 194-209.

Liu, J., Xu, F., \& Lin, S. (2017). Site selection of photovoltaic power plants in a value chain based on grey cumulative prospect theory for sustainability: A case study in Northwest China. Journal of Cleaner Production, 148, 386-397.

Mahdevari, S., Shahriar, K., \& Esfahanipour, A. (2014). Human health and safety risks management in underground coal mines using fuzzy TOPSIS. Science of the Total Environment, 488, 85-99.

Mahdevari, S., Shahriar, K., \& Esfahanipour, A. (2014). Human health and safety risks management in underground coal mines using fuzzy TOPSIS. Science of the Total Environment, 488, 85-99.

Morris, P. W. (2011). A brief history of project management. In The Oxford handbook of project management.

Najafinasab, F., Karbassi, A. R., \& Ghoddousi, J. (2015). Fuzzy analytic network process approach to evaluate land and sea criteria for land use planning in coastal areas. Ocean \& Coastal Management, 116, 368-381.

Nieminen, A., \& Lehtonen, M. (2008). Organisational control in programme teams: An empirical study in change programme context. International Journal of Project Management, 26(1), 63-72.

Onu, U. P., Xie, Q., \& Xu, L. (2017). A fuzzy TOPSIS model framework for ranking sustainable water supply alternatives. Water Resources Management, 31(9), 2579-2593.

Othman, E., \& Ahmed, A. (2013). Challenges of mega construction projects in developing countries. Organization, technology \& management in construction: an international journal, 5(1), 730-746.

Pade, C., Mallinson, B., \& Sewry, D. (2008). An elaboration of critical success factors for rural ICT project sustainability in developing countries: Exploring the Dwesa case. Journal of Information Technology Case and Application Research, 10(4), 32-55.

Rockart, J. F. (1980). The changing role of the information systems executive: a critical success factors perspective.

Rubin, I. M., \& Seelig, W. (1967). Experience as a factor in the selection and performance of project managers. IEEE Transactions on Engineering Management, 3, 131-135.

Sakthivel, G., Ilangkumaran, M., \& Gaikwad, A. (2015). A hybrid multi-criteria decision modeling approach for the best biodiesel blend selection based on ANP-TOPSIS analysis. Ain Shams Engineering Journal, 6(1), 239-256.

Samolejová, A., Wicher, P., Lampa, M., Lenort, R., Kutáč, J., \& Sikorová, A. (2015). Factors of human resource planning in metallurgical company. Metalurgija, 54(1), 243-246.

Sanvido, V., Grobler, F., Parfitt, K., Guvenis, M., \& Coyle, M. (1992). Critical success factors for construction projects. Journal of construction engineering and management, 118(1), 94-111.

Şengül, Ü., Eren, M., Shiraz, S. E., Gezder, V., \& Şengül, A. B. (2015). Fuzzy TOPSIS method for ranking renewable energy supply systems in Turkey. Renewable energy, 75, 617-625.

Shenhar, J. A., \& Dvir, D. (2007). Reinventing Project Management, Harvard Business School Press.

Shyur, H. J., \& Shih, H. S. (2006). A hybrid MCDM model for strategic vendor selection. Mathematical and computer modelling, 44(7-8), 749-761.

Silvius, A. J., \& Schipper, R. P. (2014). Sustainability in project management: A literature review and impact analysis. Social Business, 4(1), 63-96. 
Silvius, A. J., \& Schipper, R. P. (2014). Sustainability in project management: A literature review and impact analysis. Social Business, 4(1), 63-96.

Su, C. M., Horng, D. J., Tseng, M. L., Chiu, A. S., Wu, K. J., \& Chen, H. P. (2016). Improving sustainable supply chain management using a novel hierarchical grey-DEMATEL approach. Journal of Cleaner Production, 134, 469-481.

Sydow, J., Lindkvist, L., \& DeFillippi, R. (2004). Project-based organizations, embeddedness and repositories of knowledge.

Thomson, A., Strickland, A. J., \& Gamble, J. E. (2001). Crafting and executing strategy. New York: McGraw-Hill, 99 , 100.

Turner, J. R., \& Müller, R. (2005). The project manager's leadership style as a success factor on projects: A literature review. Project management journal, 36(2), 49-61.

Van Marrewijk, A., Clegg, S. R., Pitsis, T. S., \& Veenswijk, M. (2008). Managing public-private megaprojects: Paradoxes, complexity, and project design. International journal of project management, 26(6), 591-600.

Wang, L., Zhang, H. Y., Wang, J. Q., \& Li, L. (2018). Picture fuzzy normalized projection-based VIKOR method for the risk evaluation of construction project. Applied Soft Computing, 64, 216-226.

Wang, J., Liu, S. Y., \& Zhang, J. (2005). An extension of TOPSIS for fuzzy MCDM based on vague set theory. Journal of systems science and systems engineering, 14(1), 73-84.

Wang, J. J., \& Yang, D. L. (2007). Using a hybrid multi-criteria decision aid method for information systems outsourcing. Computers \& Operations Research, 34(12), 3691-3700.

Wang, T. C., \& Chang, T. H. (2007). Application of TOPSIS in evaluating initial training aircraft under a fuzzy environment. Expert Systems with Applications, 33(4), 870-880.

Wang, Y. M., \& Elhag, T. M. (2006). Fuzzy TOPSIS method based on alpha level sets with an application to bridge risk assessment. Expert systems with applications, 31(2), 309-319.

Wu, C. S., Lin, C. T., \& Lee, C. (2010). Optimal marketing strategy: A decision-making with ANP and TOPSIS. International Journal of Production Economics, 127(1), 190-196.

Yang, Y. Q., Wang, S. Q., Dulaimi, M., \& Low, S. P. (2003). A fuzzy quality function deployment system for buildable design decision-makings. Automation in construction, 12(4), 381-393.

Yeo, K. T. (1995). Planning and learning in major infrastructure development: systems perspectives. International Journal of Project Management, 13(5), 287-293.

Zhang, Y., \& Han, Q. (2017). Development of electric vehicles for China's power generation portfolio: A regional economic and environmental analysis. Journal of Cleaner Production, 162, 71-85.

Zhang, L., \& Fan, W. (2013). Improving performance of construction projects. Engineering, Construction and Architectural Management.

Zhang, X., Wu, Y., Shen, L., \& Skitmore, M. (2014). A prototype system dynamic model for assessing the sustainability of construction projects. International Journal of Project Management, 32(1), 66-76.

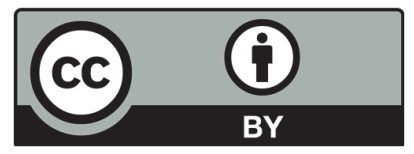

(C) 2020 by the authors; licensee Growing Science, Canada. This is an open access article distributed under the terms and conditions of the Creative Commons Attribution (CC-BY) license (http://creativecommons.org/licenses/by/4.0/). 